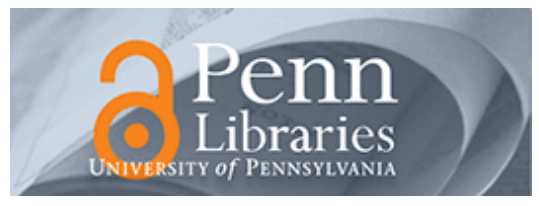

University of Pennsylvania

ScholarlyCommons

Finance Papers

Wharton Faculty Research

2009

\title{
Prohibitions on Punishments in Private Contracts
}

Philip Bond

University of Pennsylvania

Andrew F. Newman

Follow this and additional works at: https://repository.upenn.edu/fnce_papers

Part of the Finance Commons, and the Finance and Financial Management Commons

Recommended Citation

Bond, P., \& Newman, A. F. (2009). Prohibitions on Punishments in Private Contracts. Journal of Financial Intermediation, 18 (4), 526-540. http://dx.doi.org/10.1016/j.jfi.2009.07.001

This paper is posted at ScholarlyCommons. https://repository.upenn.edu/fnce_papers/358

For more information, please contact repository@pobox.upenn.edu. 


\title{
Prohibitions on Punishments in Private Contracts
}

\author{
Abstract \\ In most contemporary economies loan contracts that mandate exclusionary penalties such as \\ imprisonment or other non-pecuniary punishments for defaulting debtors are illegal, despite the fact that \\ in some cases contracting parties might gain by being able to use them. A possible rationale for \\ contracting restrictions of this type is that exclusion imposes negative externalities on individuals not \\ party to the original loan contract. We explore the ability of such externalities to account for these \\ restrictions. We contrast exclusion with enforceable collateral seizure, a widespread feature of developed \\ financial systems. We also consider "behavioral" agents who underestimate their chances of being \\ punished, and show that overconfidence of this type is a less compelling justification for restrictions on \\ exclusionary punishments than is often argued. \\ Disciplines \\ Finance | Finance and Financial Management
}




\title{
Prohibitions on Punishments in Private Contracts*
}

\author{
Philip Bond \\ Andrew F. Newman \\ University of Pennsylvania Boston University and CEPR \\ Comments welcome
}

November 2006

\begin{abstract}
In most contemporary economies loan contracts cannot mandate imprisonment or other non-pecuniary punishments for defaulting debtors. A possible rationale for contracting restrictions of this type is that imprisonment imposes negative externalities on individuals not party to the original loan contract. We explore the ability of such externalities to account for the legal restriction that private contracts cannot threaten non-pecuniary punishments. We consider both the "classical" case in which the negative externality is imposed on future trading partners, and the "behavioral" case in which the negative externality is imposed on an agent's future self.
\end{abstract}

\footnotetext{
*Both authors thank the Institute for Advanced Study for hospitality and financial support. We thank Benjamin Hermalin and Kathy Spier for helpful comments and conversations, along with audience members at the Econometric Society Meetings.
} 


\section{Introduction}

A great deal of recent research in contract theory has focused on what has become known as "contractual incompleteness." By this, economists mean that certain contingencies are impossible to include in private contracts. ${ }^{1}$ However, a second - and perhaps equally important - limitation on private contracting has received much less attention: severe restrictions are placed by the state on the punishments that can be imposed on a party that breaches a contract. That is, a contract cannot stipulate corporal punishment or imprisonment. Instead, parties can make use of only monetary incentives, which by their nature are limited. Such contracting restrictions potentially have large and important effects. In particular, if loan contracts could threaten defaulting borrowers with imprisonment, credit constraints would be ameliorated and perhaps even eliminated. ${ }^{2}$

In this paper we examine the extent to which the above restrictions on private contracting can be rationalized by a simple economic explanation, namely that the prohibited punishments would impose negative externalities on other individuals not party to the original contract. We consider two versions of this basic argument. To fix ideas, consider the specific (and standard) case of a would-be entrepreneur endowed with an investment opportunity, but lacking funds. The entrepreneur can raise financing by promising some share of future output to a lender. However, if the amount promised (i.e., the interest rate) is too high, the entrepreneur's incentive to exert effort is low, and overall surplus is negatively impacted.

In the first and more "classical" version of the externality argument, the entrepreneur can reduce the interest rate by agreeing to be imprisoned if he defaults.

\footnotetext{
${ }^{1}$ See, e.g., Hart (1995) for a survey.

${ }^{2}$ Under many circumstances, welfare losses due to credit constraints and agency problems would disappear (or nearly so) if arbitrary punishments were possible. See, e.g., Mirrlees (1999) and Mookherjee and Png (1989).
} 
The lender accepts the interest rate reduction because he knows the threat of imprisonment will induce the entrepreneur to work hard. However, with some probability the entrepreneur still defaults and is imprisoned. In this event, any third individual who would have derived positive surplus from interacting with the entrepreneur is negatively impacted. This negative externality provides a potential rationale for legal constraints on contracting.

Although simple, this externality-rationale delivers predictions that are broadly consistent with the observed incidence of contracting constraints. First, the negative externality is larger when the growth rate of the economy is high, when uncertainty about the value of future economic interactions is high, and when the number of possible future economic interactions is large. These predictions provide an explanation for why debtor's prison was eliminated in the U.S. and western Europe at roughly the same time as industrialization occurred. Second, collateral seizure - like debtor's prison - also imposes negative externalities on other individuals (it reduces the entrepreneur's ability to pledge collateral in the future), but is largely unrestricted. Our analysis provides an explanation for this asymmetry — see Section 5.

Second, we examine a more "behavioral" version of the externality argument, in which the entrepreneur overestimates his probability of success. ${ }^{3}$ Here, the externality is suffered by the entrepreneur's own future self. Again, this externality can potentially motivate legal restrictions on contracting. However, we also show that this argument is subject to important caveats. In particular, an entrepreneur who is persistently overconfident will overestimate not just his probability of success on today's project, but also the value of his time in the future. As such, he overestimates the cost of debtor's prison. We show that under some circumstances the net effect is that an overconfident agent makes too little (rather than too much) use of

\footnotetext{
${ }^{3}$ For recent research on financing overconfident entrepreneurs, see, e.g., Gervais and Goldstein (2006), Hackbarth (2004), and Landier and Thesmar (Forthcoming).
} 
punishments such as imprisonment.

Arguably the main alternative to the externality-based arguments we consider is that restrictions on punishments stem from ethical concerns. This argument seems at best incomplete, because it overlooks the fact that the state regularly uses imprisonment as a punishment for other offenses, even ones of a non-violent nature. Thus a debtor who consumes his loan instead of investing it and repaying his creditor cannot be imprisoned; while in a directly analogous setting a taxpayer who fails to pay his "debt" to the government may well suffer just such a punishment. ${ }^{4}$ Additionally, it is not immediately clear why a greater ethical problem arises in imposing a (mild) physical punishment on an individual than in stripping the same individual of valuable collateral. The later sanction is, of course, entirely legal in almost all contemporary economies.

At the same that the state persists in its use of non-monetary punishments, avenues by which contracting parties can at least partially replicate their use have been closed. Debtors' prisons no longer exist. Indentured servitude is banned. Related, personal bankruptcy prevents a creditor from exercising a claim on future earnings. Even specific performance is rarely imposed on a breaching party, and the use of noncompete clauses in labor contracts is subject to severe restrictions (and in California, is banned altogether). ${ }^{5}$

A second drawback to explaining punishment restrictions on ethical grounds is that constraints on the use of non-monetary punishments are a historically recent phenomenon. In describing the enforcement of indentured servitude contracts in early colonial America, Galenson (1984) notes that "[i]n 1612, the colony's governor

\footnotetext{
${ }^{4}$ If instead punishment restrictions arise from a need to control negative externalities, it is clearly possible for the state to both restrict their use by private parties, but to deploy them itself under some circumstances.

${ }^{5}$ See, e.g., Garmaise (2006).
} 
dealt firmly with some recaptured laborers: 'Some he appointed to be hanged Some burned Some to be broken upon wheles, others to be staked and some to be shott to death.' " Morgan (1975) considers physical punishments the main incentive device used to motivate indentured laborers. And as Chwe (1990) notes, "whipping Asian laborers was standard practice on Hawaiian sugar plantations well into this century."

Our paper is closest to the small literature that has examined a much milder restriction on private contracts, namely the non-enforceability of penalty clauses for breach. Aghion and Bolton (1987), Chung (1992), and Spier and Whinston (1995) are leading examples, all of which seek to account for this restriction as stemming from the fact that penalty clauses, while privately optimal, may be socially undesirable. In each case the social undesirability stems from the fact that penalty clauses can be used to deter entry into an industry. Also related is Diamond and Maskin (1979) who study the effects of penalty clauses on search and breach intensity in the labor market. Aghion and Hermalin (1990) and Spier (1992) have suggested that contractual constraints, among them constraints on punishments, exist as a way to prevent socially unproductive signalling.

Conceptually, our approach shares some elements of commonality with Camerer et al (2003), who seek to account for when apparently paternalistic policies (of which restrictions on non-monetary punishments is one example) can be justified on the grounds that they help boundedly rational agents more than they hurt rational agents. In common with Section 6 of the current paper, Hynes (2004) points out that the implications of exactly what inefficiencies might stem from assuming that individuals are boundedly rational are less obvious than they might at first seem. Finally, Chwe (1990) characterizes conditions under which the use of physical violence to provide incentives is privately optimal; in contrast, our focus is on when such punishments are privately optimal but socially sub-optimal. 


\section{Model}

We aim to develop a simple model that can account for legal restrictions on nonpecuniary punishments. A key difference between pecuniary and non-pecuniary punishments is that the former generally do not disrupt an individual's future productivity. (A partial exception is collateral seizure, which we consider in detail in Section 5.) In contrast, non-pecuniary incentives can have severe effects. Imprisonment and capital punishment are the clearest examples, since they absolutely eliminate an individual's future output. Corporal punishment, by causing bodily harm, will likewise tend to reduce an individual's future productivity. For want of a better word, we describe such punishments as exclusionary: in one way or another, they act to exclude an individual from future productive activity.

On the one hand, exclusionary punishments incentivize an agent to work. On the other hand, they impose a cost on the agent and his future trading partners. To make the analysis as transparent as possible, we use the simplest model capable of capturing this trade-off.

There are two periods and three individuals - one agent, $A$, (the entrepreneur in the example of the introduction) and two principals, $P_{1}$ and $P_{2}$ (e.g., lenders). In each period $t \in\{1,2\}$ the agent $A$ can contract with principal $P_{t}$, or can operate a backyard technology that produces $w$. If he contracts with principal $P_{t}$, he can either exert high effort, i.e., "work," or low effort, i.e., "shirk." If he shirks, output is $H>0$ with probability $p$, and output is 0 with probability $1-p$. High effort raises the probability of output $H$ by $\Delta p$, but requires effort $B_{t}$ from the agent. Throughout, we assume that high effort is socially efficient, i.e., $\Delta p H \geq B_{t}$. We assume also that the surplus produced when the agent contracts with the principal but shirks exceeds the backyard technology output,

$$
p H-1-w>0 \text {. }
$$


The agent and both principals are risk neutral. The agent is restricted to have nonnegative consumption. A contract in period $t$ specifies principal $P_{t}$ 's share of high output, $H-x_{t}$, and the agent's share, $x_{t}$.

(Without loss, we assume the agent receives nothing when output 0 is realized. Moreover, the agent cannot receive a negative amount: we assume he has no savings, and the only way to force him to borrow would be to threaten him with a nonpecuniary punishment — as in the contract under consideration.)

In addition to monetary incentives, principal $P_{1}$ has the option of taking some action that serves to deny the agent access to the period 2 labor market. As discussed above, corporal punishment, imprisonment and non-compete clauses all fall within this class. Accordingly, at date 1 the contract is a pair $\left(x_{1}, \pi\right)$, where $\pi$ is the probability that the agent is excluded in period 2 if the low output is realized. (Again without loss, we can assume the agent is never excluded if the high output is realized.)

For simplicity, assume that there is no discounting, and that the agent cannot store any payments received in period 1 in order to ease the second period incentive problem. Let $U_{2}$ be the agent's expected utility in period 2, provided he is not excluded. The agent's period 1 incentive constraint is thus

$$
(p+\Delta p)\left(x_{1}+U_{2}\right)+(1-p-\Delta p)(1-\pi) U_{2}-B_{1} \geq p\left(x_{1}+U_{2}\right)+(1-p)(1-\pi) U_{2}
$$

which reduces to

$$
\left(x_{1}+\pi U_{2}\right) \Delta p \geq B_{1} .
$$

We assume that in both periods the project is only possible if the principal supplies a unit of capital. Thus the principals' individual rationality constraints are

$$
(p+\Delta p)\left(H-x_{t}\right) \geq 1
$$

if the contract induces the agent to exert high effort, and

$$
p\left(H-x_{t}\right) \geq 1
$$


otherwise. In order to focus on the interesting case in which the contracting parties use exclusionary contracts, we assume throughout that there is no way to supply the agent with purely monetary incentives in period 1 that both induce him to exert high effort and satisfy principal 1's individual rationality constraint $\left(\mathrm{P}_{1}-\mathrm{IR}-\mathrm{W}\right)$ :

$$
(p+\Delta p)\left(H-\frac{B_{1}}{\Delta p}\right)-1<0
$$

Finally, since some surplus is available at both dates, we need to specify how this surplus will be split. We adopt the standard randomized "take-it-or-leave-it" offers framework. That is, in period $t$ with probability $\theta_{t}$ the agent proposes a contract to principal $P_{t}$, who either accepts or rejects. Similarly, with probability $1-\theta_{t}$ the principal $P_{t}$ proposes a contract to the agent, who either accepts or rejects.

\section{Contracts and tomorrow's trading partners}

We start by illustrating the basic externality at work: when the agent and principal $P_{1}$ agree to use an exclusionary contract $(\pi>0)$ to incentivize the agent, they are imposing a cost on principal $P_{2}$ who no longer gets a share of the surplus in period 2 . Because of this, if left unregulated the agent and principal $P_{1}$ will use exclusionary contracts more than is socially optimal.

Throughout this section, we maintain the same assumptions about technology in period 2 as we do for period 1: in particular, since exclusionary penalties are unavailable in the last period, it is impossible to give the agent incentives to work in period 2 and simultaneously satisfy principal 2's individual rationality constraint $\left(\mathrm{P}_{t}\right.$-IR-W). That is, we assume that $(2)$ holds when $B_{2}$ replaces $B_{1}$. Given this, the agent's period 2 surplus is

$$
U_{2}=\theta_{2}(p H-1)+\left(1-\theta_{2}\right) w=w+\theta_{2}(p H-1-w)
$$


The overall social surplus when the agent shirks in period 1 is

$$
S W^{n o-i n c}=p H-1+S W_{2}
$$

where here $S W_{2}=p H-1$; while the social surplus when he works, with a contract specifying a probability of exclusion $\pi$, is

$$
S W^{i n c}(\pi)=(p+\Delta p) H-1-B_{1}+(1-(1-p-\Delta p) \pi) S W_{2}
$$

Thus

$$
S W^{i n c}(\pi)-S W^{n o-i n c}=\Delta p H-B_{1}-(1-p-\Delta p) \pi S W_{2}
$$

Agent makes offer in period 1

First, consider the case in which the agent makes the contract offer in period 1 . If he offers a contract with enough incentives to work, he sets $x_{1}$ as high as possible while satisfying principal $P_{1}$ 's individual rationality constraint, $\left(\mathrm{P}_{t^{-}} \mathrm{IR}-\mathrm{W}\right)$, i.e.,

$$
x_{1}=H-\frac{1}{p+\Delta p}
$$

and the probability of exclusion as low as possible while satisfying his own incentive constraint $\left(\mathrm{IC}_{1}\right)$, i.e.,

$$
\pi U_{2}+x_{1}=\frac{B_{1}}{\Delta p}
$$

So

$$
\pi U_{2}=\frac{B_{1}}{\Delta p}-H+\frac{1}{p+\Delta p}
$$

which is strictly positive by assumption (2). The agent's utility from such a contract is

$$
\begin{aligned}
U^{i n c} & =(p+\Delta p) x_{1}-B_{1}+(1-(1-p-\Delta p) \pi) U_{2} \\
& =(p+\Delta p) H-1-B_{1}+U_{2}-(1-p-\Delta p) \pi U_{2}
\end{aligned}
$$


On the other hand, the agent can simply propose $x_{1}=H-\frac{1}{p}$ and $\pi=0$, which by assumption (2) fails to supply sufficient incentives to induce him to work. The agent's utility is then

$$
U^{n o-i n c}=p x_{1}-1+U_{2}=p H-1+U_{2}
$$

Thus the agent's gain from offering a contract with a enough incentives to get him to work is the increase in expected output (since he makes the offer, he is the residual claimant), net of the cost of working $B_{1}$, and the expected cost of exclusion:

$$
U^{i n c}-U^{n o-i n c}=\Delta p H-B_{1}-(1-p-\Delta p) \pi U_{2}
$$

So

$$
\left(U^{i n c}-U^{n o-i n c}\right)-\left(S W^{i n c}(\pi)-S W^{n o-i n c}\right)=(1-p-\Delta p)\left(\pi S W_{2}-\pi U_{2}\right)>0
$$

That is, the agent's private gains from using an exclusionary contract always exceed the social gains. In slightly more detail,

\section{Proposition 1 (Agent's bias)}

The agent views the gain from supplying incentives using an exclusionary contract as higher than the social gains by an amount

$$
\left(\frac{1}{p+\Delta p}-1\right)\left((p+\Delta p)\left(\frac{B_{1}}{\Delta p}-H\right)+1\right)\left(\frac{S W_{2}}{U_{2}}-1\right)
$$

The bias is more pronounced when the agent's period 2 bargaining power is lower and when his period 2 "outside option" $w$ is lower. The bias tends to 0 as as the agent's period 2 bargaining power approaches 1.

Proof of Proposition 1: Substituting in for $\pi$ from (5) gives the agent's bias in favor of using an exclusionary contract (6). Increasing either $\theta_{2}$ or $w$ increases $U_{2}$, which reduces the bias. 
Will the agent's bias actually lead him to propose an exclusionary contract when it is socially inefficient to do so? ${ }^{6}$ The answer is yes. From above, the exclusionary contract is socially efficient if and only of

$$
\Delta p H-B_{1} \geq(1-p-\Delta p) \pi S W_{2}
$$

where we know that $\pi$ is a linear and increasing function in $B_{1}$. Define $B_{0}$ as the value of $B_{1}$ at which pure wage incentives can be used to incentivize the agent, i.e. (2) holds at equality. So there exists $B^{*}>B_{0}$ such that an exclusionary contract is socially efficient if and only if $B_{1} \in\left[B_{0}, B^{*}\right]$. See Figure 1.

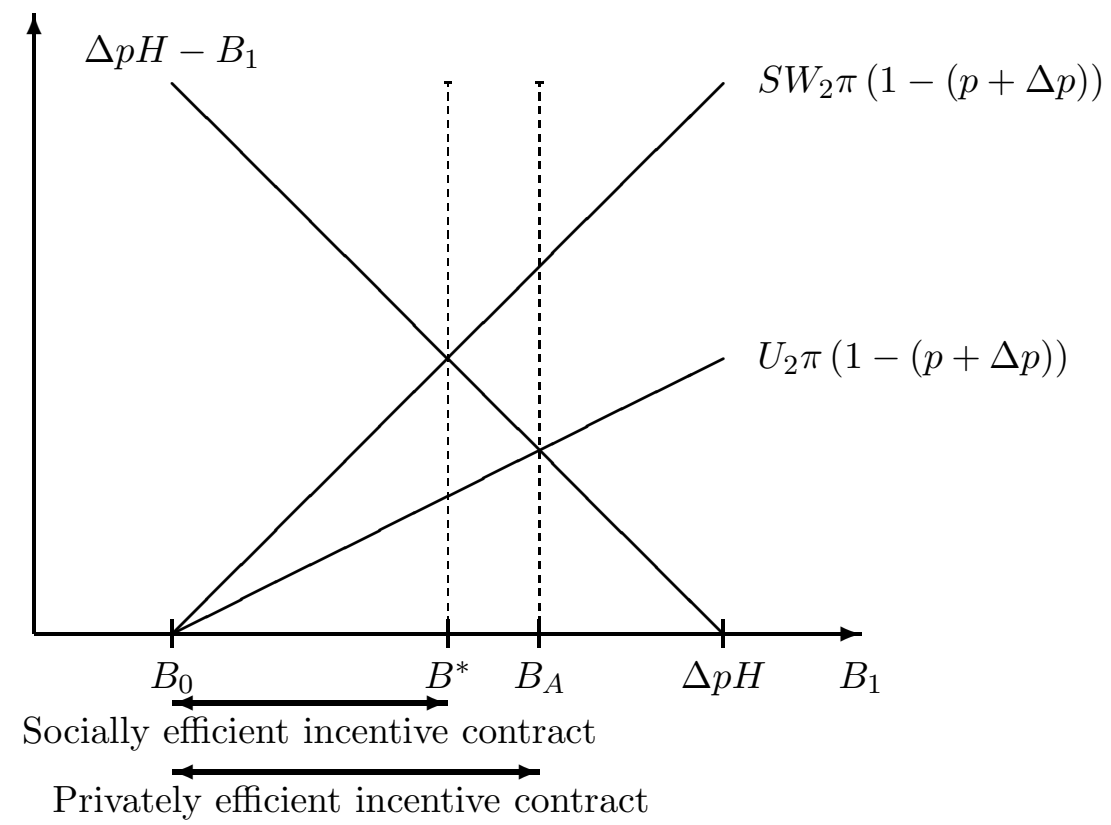

Figure 1: Use of incentive contract when agent makes offer in period 1

Similarly, an exclusionary contract is attractive to the agent if and only if

$$
\Delta p H-B_{1} \geq(1-p-\Delta p) \pi U_{2}
$$

\footnotetext{
${ }^{6}$ In principle, it is possible that the bias tends to zero as the social inefficiency from the exclusionary contract tends to zero.
} 
So again, there exists a $B_{A}>B_{0}$ such that an exclusionary contract is used by private contracting parties if and only if $B_{1} \in\left[B_{0}, B_{A}\right]$. And from Proposition 1 we know that $B_{A}>B^{*}$. So we have established:

\section{Proposition 2 (Misuse of exclusionary contracts)}

If $B_{1} \in\left(B^{*}, B_{A}\right]$ and the agent makes the contract proposal, then an exclusionary contract is used even though it is socially inefficient. ${ }^{7}$

\section{Principal makes offer in period 1}

Propositions 1 and 2 characterize the social inefficiencies that can arise when the agent has the ability to propose a period 1 contract that includes the threat of an exclusionary punishment. One might be tempted to conjecture that the inefficiencies are even worse when instead principal $P_{1}$ has the bargaining power. In Proposition 3 below, however, we show this is not necessarily the case.

When principal $P_{1}$ offers a contract $\left(x_{1}, \pi\right)$ that supplies sufficient incentives to induce the agent to work, his utility is $V^{i n c}=(p+\Delta p)\left(H-x_{1}\right)-1$, while if the contract does not offer sufficient incentives to work, $V^{n o-i n c}=p H-1-w$. Thus

$$
V^{i n c}-V^{n o-i n c}=\Delta p H-(p+\Delta p) x_{1}+w
$$

The agent's utility from a contract $\left(x_{1}, \pi\right)$ that induces him to work is

$$
(p+\Delta p) x_{1}-B_{1}+(1-(1-p-\Delta p) \pi) U_{2}
$$

The agent's reservation utility is $w+U_{2}$. Rewriting, it follows that the agent's individual rationality constraint is

$$
(p+\Delta p)\left(x_{1}+\pi U_{2}\right)-B_{1} \geq w+\pi U_{2}
$$

\footnotetext{
${ }^{7}$ There is also the constraint $\pi \leq 1$, which implies $B \leq \bar{B}$.
} 
Out of the various possible exclusionary contracts, the principal $P_{1}$ will certainly offer one in which the incentive constraint $\left(\mathrm{IC}_{1}\right)$ holds at equality — for otherwise, the principal could simultaneously reduce both $\pi$ and $x$ without violating the agent's constraint $\left(\mathrm{A}-\mathrm{IR}_{1}\right)$. Moreover, the individual rationality constraint $\left(\mathrm{A}-\mathrm{IR}_{1}\right)$ must itself hold at equality unless the principal has maxed out on the punishment and $\pi=1$ - since otherwise the principal could increase $\pi$ and reduce $x$ without violating constraint $\left(\mathrm{IC}_{1}\right)$. From the incentive constraint $\left(\mathrm{IC}_{1}\right)$ it follows that $x_{1}+\pi U_{2}=$ $B_{1} / \Delta p$. The exclusion probability $\pi$ is then set to

$$
\pi=\max \left\{\frac{(p+\Delta p)\left(x_{1}+\pi U_{2}\right)-B_{1}-w}{U_{2}}, 1\right\}=\max \left\{\frac{\frac{p B_{1}}{\Delta p}-w}{U_{2}}, 1\right\} .
$$

Our main result is:

\section{Proposition 3 (Principal 1's bias is smaller)}

The principal $P_{1}$ proposes an exclusionary contract over a strictly smaller region of the parameter space than does the agent.

At first sight, this result might appear surprising: after all, principal $P_{1}$ does not care directly about whether or not the agent is excluded from working in period 2, and so one might guess that the principal would be more inclined to use an exclusionary contract.

To understand Proposition 3, it is useful to start by noting that the result does not say that the agent is excluded with higher probability when the principal has the bargaining power. Specifically, suppose that parameters are such that both the principal and agent would propose an exclusionary contract. Under these circumstances, the principal proposes a contract with a higher exclusion probability - exactly as one would expect. ${ }^{8}$

\footnotetext{
${ }^{8}$ To see this, recall that the agent's incentive constraint $\left(\mathrm{IC}_{1}\right)$ holds at equality, regardless of who
} 
Instead, what Proposition 3 does say is that there are conditions under which the agent would propose an exclusionary contract but the principal would not. Loosely speaking, the reason is that quite a high exclusion probability is required to give principal $P_{1}$ more than $p H-1-w$, his payoff under a non-exclusionary contract when he makes the contract offer. As such, an exclusionary contract only benefits principal $P_{1}$ if it is quite socially costly - and this makes the contract less likely to be viable.

In more detail, suppose that parameter values are such that the agent is exactly indifferent between proposing an exclusionary contract and a non-exclusionary contract. The expected utility of principal $P_{1}$ is 0 , and the expected utility of the agent is $p H-1+U_{2}$. Now, suppose that the principal $P_{1}$ instead makes the contract offer. His equilibrium expected utility must be at least $p H-1-w>0$. To achieve this, the contract must offer the agent a lower monetary transfer than when the agent makes the offer. To supply incentives for the agent to work, the principal-proposed contract would then have to threaten a higher probability of exclusion. But the combined utility of the principal $P_{1}$ and the agent is then strictly lower than when the agent makes the offer. As such, there is no exclusionary contract that can provide the required reservation utilities of $w+U_{2}$ to the agent and $p H-1-w$ to principal $P_{1}$. Proof of Proposition 3: There are two cases to consider: $\pi=1$ and $\pi<1$. First, consider the (easier) case $\pi=1$. Here, the payment $x_{1}=B_{1} / \Delta p-U_{2}$ and so from (7)

$$
V^{i n c}-V^{n o-i n c}=\Delta p H-(p+\Delta p)\left(\frac{B_{1}}{\Delta p}-U_{2}\right)+w
$$

makes the contract offer. Since the principal's expected payoff is clearly higher when he makes the proposal, the monetary transfer $x$ is lower in this case - and so the exclusion probability is in turn higher, for otherwise the incentive constraint would not hold. 
Since $\pi=1$ is equivalent to $p B_{1} / \Delta p-w \geq U_{2}$,

$$
V^{i n c}-V^{n o-i n c} \leq \Delta p H-B_{1}-(1-p-\Delta p) U_{2} \leq U^{i n c}-U^{n o-i n c} .
$$

Second, consider the case $\pi<1$. Here, $x_{1}=w+\frac{(1-p) B_{1}}{\Delta p}$ and $\pi U_{2}=\frac{B_{1}}{\Delta p}-x_{1}$. Straightforward algebraic manipulation implies

$$
\begin{aligned}
V^{n o-i n c} & =U^{n o-i n c}-\left(w+U_{2}\right) \\
V^{i n c} & =\left(U^{i n c}-\left(w+U_{2}\right)\right)(p+\Delta p) .
\end{aligned}
$$

Clearly if $U^{i n c}<w+U_{2}<p H-1+U_{2}=U^{n o-i n c}$ then the agent will never propose an exclusionary contract, and nor will principal $P_{1}$ since $V^{i n c}<0$. On the other hand, if $U^{i n c} \geq w+U_{2}$ then we have

$$
V^{i n c}-V^{n o-i n c}=U^{i n c}-U^{n o-i n c}-(1-p-\Delta p)\left(U^{i n c}-\left(w+U_{2}\right)\right) \leq U^{i n c}-U^{n o-i n c} .
$$

Propositions 1 and 3 together imply that constraints on contractual punishments are more likely to be appropriate when the agent is in a relatively powerful bargaining position today, but will not be tomorrow.

\section{Uncertainty, growth and mobility}

Historically, the introduction of restrictions on exclusionary punishments roughly coincides with industrialization. Important features of industrialization include not just an increase in the overall growth rate, but also an increase in uncertainty and mobility. In this section we extend our basic model to account for these features, and examine the implications for the desirability of contracting restrictions.

Specifically, suppose that the value of principal $P_{2}$ 's project is stochastic, with a positive probability that $p H-1<w$. This uncertainty is publicly resolved after 
period 1 , but before period 2. So the expected social surplus when the agent is not excluded is

$$
S W_{2}=E[\max \{p H-1, w\}],
$$

while the agent's expected utility is

$$
U_{2}=w+\theta E[\max \{p H-1-w, 0\}]=(1-\theta) w+\theta S W_{2}
$$

What effect does this have on the inefficiency, or otherwise, of private contracting decisions? We focus for now on the case where the agent has all the bargaining power in period 1. On the one hand, note that

$$
\begin{aligned}
U^{i n c}-U^{n o-i n c} & =\Delta p H-B_{1}-(1-p-\Delta p) \pi U_{2} \\
& =\Delta p H-B_{1}-(1-p-\Delta p)\left(\frac{B_{1}}{\Delta p}-H+\frac{1}{p+\Delta p}\right)
\end{aligned}
$$

so that the agent's decision as to whether or not to use an exclusionary contract is independent of the surplus available in period 2. On the other hand, it is immediate from Proposition 1 that the magnitude of the agent's bias in favor of exclusionary contracts is increasing in the social surplus $S W_{2}$. Thus we have:

\section{Corollary 1 (Growth and uncertainty)}

Both (1) an increase in the growth rate (higher expected $p H$ in period 2), and (2) an increase in uncertainty in the value of second period $p H$, in the sense of second-order stochastic dominance, increases the agent's bias (relative to the social optimum) in favor of using an exclusionary contract.

Historically, this is consistent with the fact that moves to circumvent the private use of exclusionary contracts have generally coincided with periods of increasing growth and change.

Moreover, note from the proof of Proposition 3 that when principal $P_{1}$ makes an offer, then whenever increasing the social surplus $S W_{2}$ increases the agent's expected 
utility $U_{2}$, it will result in the principal being more likely to choose an exclusionary contract — while at the same time making it less likely that such a contract is socially efficient.

In particular, one economic and social change that may lead both to higher growth and greater uncertainty is an increase in mobility. Specifically, suppose that instead of having the opportunity just to deal with principal $P_{2}$ at date 2 , the agent can choose instead to deal with a third principal $P_{2}^{\prime}$ who has a project with expected output $p^{\prime} H^{\prime}$. In this case the agent's expected surplus is

$$
U_{2}=w+\theta E\left[\max \left\{p H-1-w, p^{\prime} H^{\prime}-1-w, 0\right\}\right]
$$

This gives:

\section{Corollary 2 (Increased mobility)}

An increase in the agent's employment options at date 2 increases the agent's bias (relative to the social optimum) in favor of using an exclusionary contract.

\section{A brief history of debtor's prisons in the United States}

Although sometimes regarded as a medieval institution, imprisonment for debt persisted into the nineteenth century in the United States. ${ }^{9}$ Mann (2002, page 79) summarizes the situation in United States shortly after independence in the following terms: "every colony north of the Potomac, with the possible exception of New Hampshire, permitted insolvent debtors to be bound in service to their creditors without their consent, typically for as long as seven years, the standard term for indentured

\footnotetext{
${ }^{9}$ The closely related institution of bound labor was not abolished until 1867 Antipeonage Act, i.e., after slavery had been abolished in the United States. A concise legal history can be found in the Supreme Court case of Pollock vs Williams (322 U.S. 4).
} 
servants." New York did not abolish imprisonment for indebtedness until 1831, and Pennsylvania did not do so until $1842 .^{10}$

However, as early as the mid-eighteenth century there had been calls for the abolishment of debtor's prison. ${ }^{11}$ For example, a 1754 Rhode Island pamphlet, ${ }^{12}$ "The Ill Policy and Inhumanity of Imprisoning Insolvent Debtors, Fairly Stated and Discussed" stated that

it is best for Society, that his Creditors receive a Proportion of their Debts ... and his Person be sat at Liberty to seek new Employment; or that his Body be imprisoned for the Deficiency, until he pays the utmost Farthing, which is impossible?

The reference to society as a whole, and to new employment, seem very much in the same spirit as our more formal analysis above.

\section{$5 \quad$ Non-exclusionary punishments}

Up to now we have been concerned only with the use of exclusionary punishments. In practice, agents can also be punished in non-exclusionary ways. Collateral seizure is a leading example.

Although collateral seizure is not itself exclusionary, it may generate exclusionarylike effects (see, e.g., Ayotte 2007). Consider the case in which the agent has enough

\footnotetext{
${ }^{10}$ See Mann (2002, page 106).

${ }^{11}$ There is also some evidence that conditions for debt imprisonment eased prior to the $1830 \mathrm{~s}$. Coleman (1965) and Randall (1952) both report that insolvent debtors were released once all their property had been handed over. That is, imprisonment was used only to enforce collateral collection. Feer (1961) reports that as early as 1737, in Massachusetts debtors were no longer bound to work for creditors to repay their debt.

${ }^{12}$ See Mann (2002, page 83.
} 
collateral to sign an incentive contract even in the second period. Then if the first principal seizes this collateral, an incentive contract is no longer possible in the second period. The agent is effectively "excluded" from working in an incentivized way.

In practice, legal constraints on collateral seizure are much weaker than constraints on purely exclusionary punishments. In this section we extend our basic model to offer an explanation.

Specifically, suppose the agent has collateral (a house, for example) with value $K \geq w$ to the agent. Assume that it is non-divisible, and that both principals $P_{1}$ and $P_{2}$ can impose randomized seizure of the house as a punishment for low output. Let $\chi_{1}$ and $\chi_{2}$ be the probabilities of seizure by the two principals respectively.

In order to ensure that collateral is economically relevant, we assume that

$$
H-\frac{1}{p+\Delta p}+K \geq \frac{B_{t}}{\Delta p}
$$

so that if the principal receives the minimum amount consistent with his individual rationality constraint (i.e., $\frac{1}{p+\Delta p}$ when output is high), there is a collateral seizure probability $\chi_{t} \leq 1$ that gives the agent enough incentives. For expositional ease, we focus on the case in which the agent has all the bargaining power in period 1. Finally, we also assume that $K$ has zero-value to the principals. This assumption is made solely to make the punishment $K$ as closely comparable to the exclusionary punishment as possible, and our results would actually be strengthened if $K$ were valued by the principal.

\section{The comparative social costs of collateral seizure and exclusion}

When principal $P_{1}$ provides the agent with incentives, he does so by threatening to impose a punishment (collateral seizure or exclusion) on the agent with some probability ( $\chi_{1}$ and $\pi$ respectively). When the agent proposes the contract, he 
proposes $x_{1}=H-\frac{1}{p+\Delta p}$ regardless of which punishment device is used. The expected punishment incurred by the agent when output is low must then satisfy

$$
\Delta p\left(x_{1}+(\text { cost of punishment to agent }) \times(\text { prob. of punishment })\right)=B_{1} .
$$

The equilibrium social cost is then

$$
\frac{\text { social cost of punishment }}{\text { cost of punishment to agent }} \times\left(\frac{B_{1}}{\Delta p}-x_{1}\right) \text {. }
$$

Since $x_{1}$ is independent of the type of punishment used, the social cost is minimized when the ratio of the social cost of punishment to the agent's disutility from the punishment is minimized.

Notationally, let $U_{2}^{K}$ and $U_{2}^{-K}$ respectively denote the agent's expected utility in period 2 when he still has collateral, and when he does not. Likewise, let $S W_{2}^{K}$ and $S W_{2}^{-K}$ denote the expected social welfare. When the punishment threatened by principal $P_{1}$ is exclusion in period 2 ,

$$
\frac{\text { social cost of punishment }}{\text { cost of punishment to agent }}=\frac{S W_{2}^{K}}{U_{2}^{K}},
$$

while when the punishment threatened by principal $P_{1}$ is collateral seizure,

$$
\frac{\text { social cost of punishment }}{\text { cost of punishment to agent }}=\frac{S W_{2}^{K}-S W_{2}^{-K}+K}{U_{2}^{K}-U_{2}^{-K}+K} \text {. }
$$

Proposition 4 (Social loss from exclusionary punishments is worse)

If $K \geq w$, the social loss of using the exclusionary punishment to incentivize the agent in period 1 is greater than the social loss of using collateral seizure.

Proof of Proposition 4: From the discussion prior to the Proposition statement, we must show

$$
\frac{S W_{2}^{K}}{U_{2}^{K}}>\frac{K+S W_{2}^{K}-S W_{2}^{-K}}{K+U_{2}^{K}-U_{2}^{-K}}
$$


or equivalently,

$$
\left(S W_{2}^{K}-U_{2}^{K}\right) K>U_{2}^{K}\left(S W_{2}^{K}-S W_{2}^{-K}\right)-S W_{2}^{K}\left(U_{2}^{K}-U_{2}^{-K}\right) .
$$

When the agent makes the contract offer in period 2 he captures all the social surplus, while when the principal makes the offer the agent's individual rationality constraint binds. So $U_{2}^{K}$ and $S W_{2}^{K}$ are related by

$$
U_{2}^{K}=S W_{2}^{K}-(1-\theta)\left(\left(\text { social surplus with collateral when } P_{2} \text { makes offer }\right)-w\right) \text {. }
$$

When the agent has no collateral in period 2, it is impossible to provide the agent with incentives and the social surplus is $S W_{2}^{-K}=p H-1$ regardless of who makes the offer. So

$$
U_{2}^{-K}=S W_{2}^{-K}-(1-\theta)\left(S W_{2}^{-K}-w\right)
$$

Consequently,

$U_{2}^{K}-U_{2}^{-K}=S W_{2}^{K}-S W_{2}^{-K}-(1-\theta)\left(\left(\right.\right.$ social surplus with collateral when $P_{2}$ makes offer $)-S W_{2}^{-K}$ and (8) rewrites to

((social surplus with collateral when $P_{2}$ makes offer $\left.)-w\right)\left(K+S W_{2}^{K}-S W_{2}^{-K}\right)$

$>\left(\left(\right.\right.$ social surplus with collateral when $P_{2}$ makes offer $\left.)-S W_{2}^{-K}\right) S W_{2}^{K}$.

If when principal $P_{2}$ makes the contract offer he proposes a contract which does not provide the agent with incentives, the right-hand side of (9) is zero, and so the inequality is satisfied since certainly $S W_{2}^{K}>U_{2}^{K}$. If instead principal $P_{2}$ proposes a contract that provides the agent with incentives, it is straightforward to show that the agent does so also. (The basic argument is the same as for Proposition 3.) So in this case, the period 2 social surplus with collateral is independent of who makes the offer, and equals $S W_{2}^{K}$. Inequality (9) reduces to

$$
K\left(S W_{2}^{K}-w\right)>w\left(S W_{2}^{K}-S W_{2}^{-K}\right)
$$


which is certainly satisfied since $K \geq w$ and $S W_{2}^{-K}=p H-1>w$ by (1).

\section{Contracting constraints}

Proposition 4 above says that using collateral to provide incentives imposes lower social costs than does using exclusionary threats to achieve the same end. This suggests that legal constraints on the use of punishments should be targeted at reducing the use of exclusionary contracts.

Here, we consider optimal punishment constraints in a very simple policy environment. In particular, we assume that the only feasible constraints are all-or-nothing in nature - in the sense that either a complete ban is placed on using an incentive device (collateral seizure or exclusion or both) or no restriction is imposed at all. We will establish:

\section{Proposition 5 (No total ban on seizing collateral)}

It is never an optimal policy to ban principals from seizing the agent's collateral $K$.

Proof of Proposition 5: The key step in proving Proposition 5 is to show that it is always better to ban just exclusionary penalties and allow collateral seizure than to ban both. To see this, consider total social surplus when just collateral seizure is allowed. If the agent does not propose collateral seizure in one period, he will not do so in the other; and so neither will principal $P_{2} \cdot{ }^{13}$ In this case, a ban on collateral seizure has no impact. If instead the agent proposes collateral seizure in one period, he will do so in both. In this case, social surplus is

$$
(p+\Delta p) H-B_{1}-1-(1-p-\Delta p) \chi_{1}\left(K+S W_{2}^{K}-S W_{2}^{-K}\right)+S W_{2}^{K}
$$

\footnotetext{
${ }^{13}$ We are assuming that in period 1 the agent always proposes the contract. However, if the agent does not propose collateral seizure in period 1 , neither would principal $P_{1}$.
} 


$$
\begin{aligned}
= & (p+\Delta p) H-B_{1}-1-(1-p-\Delta p) \chi_{1}\left(K+U_{2}^{K}-U_{2}^{-K}\right) \\
& -(1-p-\Delta p) \chi_{1}\left(\left(S W_{2}^{K}-S W_{2}^{-K}\right)-\left(U_{2}^{K}-U_{2}^{-K}\right)\right)+S W_{2}^{K} .
\end{aligned}
$$

Here, we have decomposed the expected social loss of imposing the punishment, i.e. $(1-p-\Delta p) \chi_{1}\left(K+S W_{2}^{K}-S W_{2}^{-K}\right)$, into the deadweight loss inflicted on the agent, $(1-p-\Delta p) \chi_{1}\left(K+U_{2}^{K}-U_{2}^{-K}\right)$, and the remainder. Observe the deadweight loss inflicted the agent must be less than the agent's expected gain from using the incentive contract, which is $\Delta p H-B_{1}$. It follows that expression (10) exceeds $(p+\Delta p) H-B_{1}-1-\left(\Delta p H-B_{1}\right)-\left(S W_{2}^{K}-S W_{2}^{-K}\right)+S W_{2}^{K}=p H-1+S W_{2}^{-K}$ which is exactly the social surplus available if both possible punishments are banned.

To complete the proof, we must also show that it is better to ban exclusion and allow collateral seizure than to ban collateral seizure and allow exclusion. Suppose first that when exclusion is allowed, it is used in the period 1 contract. In this case, collateral seizure would be used in the period 1 contract if it were allowed. It follows directly from Proposition 4 that social surplus is higher when exclusion is banned since collateral seizure is less socially costly. Moreover, allowing collateral seizure directly increases period 2 surplus when the agent still has collateral in that period. Finally, if exclusion is not used in equilibrium even when it is allowed, social surplus when collateral seizure is banned is simply $p H-1+S W_{2}^{-K}-$ and we have already shown that allowing collateral seizure leads to a higher social surplus.

The basic intuition for Proposition 5 is as follows. The externality produced by collateral seizure is that with some probability principal $P_{2}$ is left unable to incentivize the agent to work. Under an outright ban on collateral seizure, however, principal $P_{2}$ can never incentivize the agent. Of course, collateral seizure also imposes a deadweight cost in that the agent values the collateral more than the principal ${ }^{14}$ — but this

\footnotetext{
${ }^{14}$ As noted, for expositional ease we have made the extreme assumption that the principal does
} 
component of the cost is internalized by the agent. It follows that banning collateral pledging can only reduce social welfare.

In our model, a lawmaker might still like to ban collateral seizure by principal $P_{1}$, while continuing to allow it for principal $P_{2}$. Nonetheless, Proposition 4 above shows that in many circumstances banning exclusionary punishments should still be a higher priority, even if finer-tuned policies of this type are possible. And in practice, it may not straightforward for a legal system to identify whether or not a particular principal is $P_{1}$ or $P_{2}$.

In contrast to Proposition 5, from Proposition 4 and our previous analysis we know it may be optimal to ban the use of exclusionary punishments. Doing so leads the period 1 contracting parties to switch to using collateral seizure to provide incentives, which are typically less socially damaging.

\section{Over-confidence}

We now turn to a second "externality" explanation that is often proposed for courts' refusal to enforce exclusionary contracts, namely that this is to protect agents from their own over-confidence. This is an old idea — as long ago as 1935, McCormick wrote in his legal treatise that: ${ }^{15}$

It is a characteristic of men, however, that they are likely to be beguiled by the "illusions of hope," and so feel so certain of their ability to carry out their engagements in future, that their confidence leads them to be willing to make extravagant promises and commitments as to what they are willing to suffer if they fail.

not value the collateral at all.

${ }^{15}$ See page 601 . 
Many recent studies support this claim, by showing that individuals systematically overestimate their skill. ${ }^{16}$

Although the idea that contracting constraints are needed to protect agents from themselves is intuitive, in this section we will exhibit what we view as three important caveats.

First, even if the agent overestimates the benefits of the incentive contract relative to the no-incentive contract, the social costs related to him mistakenly choosing the incentive contract are reduced by over-confidence. The reason is that overconfident agents need less high-powered incentives, and so the exclusion probability $\pi$ can be set lower.

Second, and related, if the degree of over-confidence is large enough then there may be no need for an exclusionary contract at all. Of course, overconfident agents may still sign up for incentive contracts when they should not do so; but now this represents an aggregate social benefit, since working is socially efficient.

Third, if an individual is persistently overconfident of his ability this will lead him not just to underestimate the risk of failure today, but tomorrow also. The consequence of this is that he overestimates the value of not being excluded. This leads him to act more cautiously when considering the merits of an exclusionary contract.

\section{Assumptions}

Formally, we assume that an agent (incorrectly) believes that by exerting effort he can raise the probability of success by $\Delta q>\Delta p$. Moreover, the agent is aware that others do not share this opinion, i.e., he knows that principals believe that effort only

\footnotetext{
${ }^{16}$ To give just one (well-known) example, individuals systematically overestimate their driving ability — see Svenson (1981).
} 
raises the success probability by $\Delta p$. Finally, we assume that principals know that they are dealing with an overconfident agent, and that this fact is common knowledge.

In this section we want to explore the ability of overconfidence, as opposed to externalities, to account for observed restrictions on contracting. To cleanly distinguish the two cases we consider the following variant of our environment:

In period 1 the agent contracts with principal $P_{1}$, just as before. Exclusionary contracts are potentially useful because the agent needs to be given incentives in this period. For expositional conciseness, we assume that the agent makes the contract offer in period 1 . In period 2, the agent no longer meets a principal. Instead, he has direct ownership of a productive technology that yields an output $(p+\Delta p) H-1$ if he exerts effort $B_{2}$, and an output of $p H-1$ otherwise. If the agent is excluded as a punishment for low output in period 1, he loses access to this technology, and receives zero utility.

The key feature of this modified environment is that there is no longer an externalitybased rationale for restricting the use of exclusionary punishments. Now, the agent bears all the social cost himself. However, the agent's misperception of the efficacy of his effort may still generate a socially inefficient outcome if it leads the agent to accept a greater expected punishment than the social surplus produced by exerting effort actually justifies. That is, instead of constraints on contracting serving to protect future trading partners, any constraints will instead stem from the need to protect the agent from himself.

Let $U_{2}$ denote the agent's true expected utility in period 2 , and $\hat{U}_{2}$ the agent's belief about $U_{2}$. As we will see, $U_{2}$ and $\hat{U}_{2}$ may differ. In period 1 , the agent works only under a contract $\left(x_{1}, \pi\right)$ that satisfies

$$
\left(x_{1}+\pi \hat{U}_{2}\right) \Delta q \geq B_{1}
$$


Principal 1 accepts such a contract if and only if

$$
(p+\Delta p)\left(H-x_{1}\right)-1 \geq 0
$$

Since the agent proposes the incentive contract, he will always offer

$$
\hat{x}_{1}=H-\frac{1}{p+\Delta p}
$$

Moreover, whenever exclusion incentives are used (i.e. $\pi>0$ ) the agent's preferred contract $\left(\hat{x_{1}}, \hat{\pi}\right)$ satisfies

$$
\hat{x}_{1}+\hat{\pi} \hat{U}_{2}=\frac{B_{1}}{\Delta q}
$$

Observe that because the agent is overconfident of success, he must be offered fewer incentives than would otherwise be the case.

\section{Overconfidence-induced social inefficiency}

The case that proponents of over-confidence as a basis for contracting constraints appear to have in mind is that where

$$
(p+\Delta p)\left(H-\frac{B_{1}}{\Delta q}\right)-1<0
$$

and $U_{2}=\hat{U}_{2}$. That is, even under over-confidence monetary incentives are insufficient to persuade the agent to work in period 1 , and the agent correctly perceives the period 2 surplus. Under this case, the agent's perceived welfare from offering his preferred incentive contract is

$$
\begin{aligned}
\hat{U}^{i n c} & =(p+\Delta q) \hat{x_{1}}-B_{1}-(1-p-\Delta q) \hat{\pi} \hat{U}_{2}+\hat{U}_{2} \\
& =(p+\Delta p) H-1-B_{1}-(1-p-\Delta p) \hat{\pi} \hat{U}_{2}+\hat{U}_{2}+(\Delta q-\Delta p)\left(\hat{x_{1}}+\hat{\pi} \hat{U}_{2}\right) \\
& =S W^{i n c}+\left(1-\frac{\Delta p}{\Delta q}\right) B_{1}
\end{aligned}
$$


where $S W^{i n c}$ denotes the true social welfare if the incentive contract is used, i.e.,

$$
S W^{i n c}=(p+\Delta p) H-1-B_{1}-(1-p-\Delta p) \hat{\pi} U_{2}+U_{2}
$$

If the incentive contract is not used, the agent's welfare is

$$
\hat{U}^{n o-i n c}=p H-1+\hat{U}_{2}=S W^{n o-i n c}
$$

The agent believes that the gain in using the incentive contract instead of the noincentive contract is $\hat{U}^{i n c}-\hat{U}^{n o-i n c}$. The true gain, both to the agent and to social welfare, is $S W^{i n c}-S W^{n o-i n c}$. The agent's bias in favor of the incentive contract is consequently

$$
\left(\hat{U}^{i n c}-\hat{U}^{n o-i n c}\right)-\left(S W^{i n c}-S W^{n o-i n c}\right)=\left(1-\frac{\Delta p}{\Delta q}\right) B_{1}>0
$$

In this case holds, the "classical" intuition is correct: the agent underestimates the probability of failure, and so overestimates the value of binding himself using socially costly incentives. As a consequence, he may wrongly choose to use a contract which employs the threat of exclusion as an incentive device.

Even in this case, however, the social costs of overconfidence are not monotonic. In particular, suppose that $S W^{i n c}-S W^{n o-i n c}<0$, so that using the exclusionary contract destroys social surplus. The agent makes the socially efficient decision for all $\Delta q$ below some critical value, $\delta$ say. As $\Delta q$ increases from just below $\delta$ to just above $\delta$, the social cost of overconfidence becomes positive. However, as $\Delta q$ increases further, the social cost of overconfidence declines, since the exclusion probability $\hat{\pi}$ can be lowered.

\section{Do overconfident agents need to be excluded?}

A second caveat to the above argument for restrictions on contracting is that for $\Delta q$ large enough it is quite possible for inequality (11) not to hold, even though (2) does. 
In this case, there is simply no need to use exclusion as a punishment, i.e., $\hat{\pi}=0$, and overconfidence has no social cost at all.

\section{Overconfidence about tomorrow}

A third caveat relates to the agent's overestimate of the value of tomorrow's surplus. Consider again the case where pure monetary incentives cannot be used to induce the agent to work in period 1, i.e., (11) holds.

Thus far we have assumed that while the agent misperceives the effect of effort on the success probability today $(\Delta q>\Delta p)$ and so overestimates his expected utility in period 1 , he correctly perceives his expected utility in period 2 (i.e. $\hat{U}_{2}=U_{2}$ ). In many respects, however, the more natural assumption is that if the agent is overconfident today he will be overconfident about tomorrow also. In this case, $\hat{U}_{2}>U_{2}$.

The important point to note is that overconfidence about tomorrow acts to provide a countervailing force to the agent's tendency to sign up for incentive contracts too often. He overestimates the cost of exclusion in period 2, and so may actually under-utilize the incentive contract.

Specifically, consider the case in which the agent believes that effort in either period 1 or 2 raises the probability of high output by $\Delta q>\Delta p$. In this case, $\hat{U}_{2}-U_{2}=(\Delta q-\Delta p) H>0$. The agent's perceived utility in period 1 from using the incentive contract is now

$$
\begin{aligned}
\hat{U}^{i n c}= & (p+\Delta q) \hat{x}_{1}-B_{1}-(1-p-\Delta q) \hat{\pi} \hat{U}_{2}+\hat{U}_{2} \\
= & p H-1-B_{1}-(1-p-\Delta p) \hat{\pi} \hat{U}_{2}+\hat{U}_{2}+(\Delta q-\Delta p)\left(\hat{x_{1}}+\hat{\pi} \hat{U}_{2}\right) \\
= & p H-1-B_{1}-(1-p-\Delta p) \hat{\pi} U_{2}+U_{2}+\left(1-\frac{\Delta p}{\Delta q}\right) B_{1}+\left(\hat{U}_{2}-U_{2}\right) \\
& -(1-p-\Delta p) \hat{\pi}\left(\hat{U}_{2}-U_{2}\right)
\end{aligned}
$$




$$
=S W^{i n c}+\left(1-\frac{\Delta p}{\Delta q}\right) B_{1}+\left(\hat{U}_{2}-U_{2}\right)-(1-p-\Delta p) \hat{\pi}\left(\hat{U}_{2}-U_{2}\right)
$$

while

$$
\hat{U}^{n o-i n c}=p H-1+\hat{U}_{2}=S W^{n o-i n c}+\left(\hat{U}_{2}-U_{2}\right)
$$

Thus the agent's bias in favor of the incentive contract relative to the true gain or loss in social welfare is

$$
\begin{aligned}
\left(\hat{U}^{i n c}-\hat{U}^{n o-i n c}\right)-\left(S W^{i n c}-S W^{n o-i n c}\right) & =\left(1-\frac{\Delta p}{\Delta q}\right) B_{1}-(1-p-\Delta p) \hat{\pi}\left(\hat{U}_{2}-U_{2}\right) \\
& =(\Delta q-\Delta p)\left(\frac{B_{1}}{\Delta q}-\hat{\pi}(1-p-\Delta p) H\right)(12)
\end{aligned}
$$

The direction of the agent's bias is no longer clear. On the one hand, he underestimates the probability of exclusion. But there is an offsetting effect - he overestimates the cost that being excluded imposes on him. ${ }^{17}$

Although it is hard to sign expression (12) in general, we can show that if the surplus produced without expending effort is small, then an agent who is overconfident in both periods will never wrongly use an incentive contract:

\section{Proposition 6 (Overconfident agents don't overuse exclusion punishments)}

If the surplus $p H-1$ produced by a shirking agent is small enough then an overconfident agent will never use an incentive contract in period 1 when it is in fact socially suboptimal to do so.

Proof of Proposition 6: First, notice that the incentive contract is only socially suboptimal if the probability that exclusion is imposed is quite high. That is, since

$$
S W^{i n c}-S W^{n o-i n c}=\Delta p H-B_{1}-(1-p-\Delta p) \hat{\pi} U_{2}
$$

\footnotetext{
${ }^{17}$ Recall that

$$
\hat{\pi}=\frac{1}{\hat{U}_{2}}\left(\frac{B_{1}}{\Delta q}-H+\frac{1}{p+\Delta p}\right) .
$$
}


then $S W^{i n c}-S W^{n o-i n c}<0$ is equivalent to

$$
(1-p-\Delta p) \hat{\pi}>\frac{\Delta p H-B_{1}}{U_{2}}
$$

From expression (12), the agent's bias in favor of the incentive contract is certainly less than

$$
(\Delta q-\Delta p)\left(\frac{B_{1}}{\Delta q}-\frac{\Delta p H-B_{1}}{U_{2}} H\right)
$$

Now, $B_{1} / \Delta q<B_{1} / \Delta p<H$. To complete the proof, simply note that as $p H-1 \rightarrow 0$ then $\Delta p H-B_{1} \rightarrow U_{2}$, and so the agent's bias must be actually be negative. That is, the agent would not use the incentive contract if it is socially suboptimal to do so.

\section{Contracting constraints}

We conclude this section by noting that even when the parameter values are such that an overconfident agent is wrongly tempted to use an incentive contract that deploys exclusionary punishments, the implications for optimal constraints on contracting differ sharply from the externality case explored in Sections 2 - 5 .

Our main observation is as follows. In Section 5 we demonstrated that when punishment constraints are motivated by externality concerns then there is a much stronger case to be made for prohibiting the use of exclusionary punishments than collateral seizure. The key reason is that, as demonstrated by Proposition 4, the social cost of exclusionary punishments is greater than the social cost of collateral seizure. In contrast, no such distinction exists if punishment constraints stem solely from a desire to protect overconfident agents from themselves. In this latter case, the agent fully internalizes the social deadweight loss of any punishment — social inefficiency, if any, stems only from agents underestimating the probability that the 
punishment will be imposed. This is true regardless of whether the punishment is exclusionary, or takes the form of collateral seizure.

In practice lawmakers appear to have been much more concerned with placing restrictions on exclusionary punishments than on collateral seizure. Today most forms of exclusionary punishment are entirely prohibited. In contrast, only weak constraints exist to prevent an agent from pledging any collateral he possesses. Moreover, those restrictions that do exist, such as bankruptcy exemptions in some U.S. states, postdate the abolition of most forms of exclusionary punishments.

We should make clear that we are not arguing that overconfidence plays no role in the existence of contracting constraints. Instead, our point is that it is hard to see how overconfidence alone can account for the apparent much greater concern with restricting the use of what we have termed "exclusionary" punishments than the use of straightforward collateral seizure.

\section{Conclusion}

In this paper we have explored the extent to which an important constraint on private contracting, namely the prohibition of non-pecuniary punishments, can be rationalized by the negative externalities these punishments impose on other individuals. Both the timing of when punishments such as debtor's prison were eliminated, and the fact that collateral seizure is not similarly restricted, are consistent with the implications of our model. Our analysis also indicates that the extent to which behavioral biases lead to socially inefficient private contracts is more complicated than often appreciated.

Inevitably our analysis omits some important issues. Two deserve particular mention. First, we have assumed throughout that the agent and principal $P_{2}$ cannot offer to share the period 2 surplus with principal $P_{1}$ in exchange for "forgiveness." 
Renegotiation of this form has the potential to undo the negative externality at the heart of the paper. Clearly some forms of non-pecuniary punishment, notably corporal punishment, cannot be renegotiated once they have been inflicted. For other forms of punishment, such as imprisonment, a version of our results would continue to hold provided renegotiation is not perfect.

A second issue that we have ignored is the extent to which the outputs of different individuals are correlated. Consider an economy populated by a large number of agents, with projects that are highly correlated. If exclusionary contracts are used in such an economy, the supply of agents will be substantially reduced when projects produce low output. As a consequence, the bargaining power of any non-excluded agent will be raised. This effect means that, in equilibrium, at least some agents will refrain from writing socially inefficient exclusionary contracts in period 1 , since given their high bargaining power in period 2 they suffer most of the cost. We leave a fuller analysis of the equilibrium outcomes of such an economy for future research.

\section{References}

Philippe Aghion and Patrick Bolton. Contracts as a barrier to entry. American Economic Review, pages 388-401, June 1987.

Philippe Aghion and Benjamin Hermalin. Legal restrictions on private contracts can enhance efficiency. Journal of Law, Economics and Organization, 6(2):381-409, Fall 1990.

Kenneth Ayotte. Bankruptcy and entrepreneurship: the value of a fresh start. Journal of Law, Economics and Organization, 23(1), Spring 2007.

Colin Camerer, Sam Issacharoff, George Lowenstein, Ted O’Donoghue, and Matthew 
Rabin. Regulation for conservative: Behavioral economics and the case for "asymmetric paternalism". University of Pennsylvania Law Review, 151, January 2003.

Tai-Yeong Chung. On the social optimality of liquidated damage clauses: An economic analysis. Journal of Law, Economics, and Organization, 8(2):280-305, 1992.

Michael Suk-Young Chwe. Why were workers whipped? pain in a principal-agent model. Economic Journal, 100(403):1109-1121, December 1990. 403.

Peter J Coleman. The insolvent debtor in Rhode Island 1745-1828. William and Mary Quarterly, 22(3):413-434, July 1965.

Peter A. Diamond and Eric Maskin. An equilibrium analysis of search and breach of contract, i: Steady states. Bell Journal of Economics, 10:282-316, Spring 1979. 1.

Robert A. Feer. Imprisonment for debt in Massachusetts before 1800. Mississippi Valley Historical Review, 48(2):252-269, September 1961.

David W. Galenson. The rise and fall of indentured servitude in the americas: An economic analysis. Journal of Economic History, 44(1):1-26, March 1984.

Mark Garmaise. Ties that truly bind: Non-competition agreements, executive compensation and firm investment. Working Paper, 2006.

Simon Gervais and Itay Goldstein. The positive effects of biased self-perceptions in firms. Working Paper, 2006.

Dirk Hackbarth. Managerial traits and capital structure decisions. Working Paper, 2004.

Oliver Hart. Firms, Contracts and Financial Structure. Oxford University Press, 1995. 
Richard Hynes. Overoptimism and overborrowing. Brigham Young University Law Review, 127, 2004.

Anthony T Kronman. Paternalism and the law of contracts. Yale Law Journal, 92: 763-798, april 1983.

Augustin Landier and David Thesmar. Financial contracting with optimistic entrepreneurs. Review of Financial Studies, Forthcoming.

Bruce H Mann. Republic of Debtors: Bankruptcy in the Age of American Independence. Harvard University, 2002.

James A Mirrlees. The theory of moral hazard and unobservable behaviour: Part I. Review of Economic Studies, 66(1):3-21, January 1999.

Dilip Mookherjee and Ivan Png. Optimal auditing, insurance and redistribution. Quarterly Journal of Economics, 104(2):399-415, May 1989.

Edmund Sears Morgan. American Slavery, American Freedom: : the ordeal of colonial Virginia. Norton, 1975.

Edwin T. Randall. Imprisonment for debt in America: Fact and fiction. Mississippi Valley Historical Review, 39(1):89-102, June 1952.

Kathryn E. Spier. Incomplete contracts and signalling. RAND Journal of Economics, 23(3):432-443, Autumn 1992.

Kathryn E. Spier and Michael D. Whinston. On the efficiency of privately stipulated damages for breach of contract: entry, reliance, and renegotiation. RAND Journal of Economics, 26(2):180-202, 1995.

Ola Svenson. Are we all less risky and more skillful than our fellow drivers? Acta Pschologica, 47:143-148, 1981. 